\title{
Aspectos fitossociológicos de um fragmento da floresta natural de Astronium balansae engl., no município de Bossoroca, RS $^{1}$
}

\author{
Phytosociological characteristics of a fragment of the natural forest \\ of Astronium balansae engl, in the county of Bosssoroca, RS
}

\author{
Alexandra Augusti Boligon ${ }^{2}$ Solon Jonas Longhi ${ }^{3}$ \\ Augusto Bolson Murari ${ }^{4}$ Cristiano Hack ${ }^{2}$
}

RESUMO

Este estudo objetivou conhecer a composição florística e a estrutura fitossociológica de um fragmento do Floresta Natural de Astronium balansae Engl., no município de Bossoroca, RS, Brasil. Foram demarcadas 7 unidades amostrais de $10 \times 100 m\left(1000 m^{2}\right)$ onde observou-se a ocorrência de 476 indivíduos com Circunferência à Altura do Peito $(C A P)=30 \mathrm{~cm}$, distribuídos em 35 espécies e 25 famílias. As espécies mais características e importantes da floresta foram Astronium balansae, Myrcianthes pungens, Patagonula americana, Eugenia uniflora e Parapiptadenia rigida. As famílias Myrtaceae, Meliaceae e Euphorbiaceae foram as mais representativas do fragmento florestal estudado. $O$ valor do Índice de diversidade de Shannon foi 3.

Palavras-chave: composição florística, fitossociologia, pauferro.

\section{ABSTRACT}

The study was carried out to evaluate the floristic composition and the phytosociological characteristics of a fragment of the natural forest of Astronium balansae Engl, in Bossoroca county, RS, Brazil. Seven $10 \times 100 \mathrm{~m}\left(1000 \mathrm{~m}^{2}\right)$ units were inventoried: 476 measured trees $(\mathrm{CBH}=30 \mathrm{~cm})$ were distributed in 35 species and 25 families. The most important species were Astronium balansae, Myrcianthes pungens, Patagonula americana, Eugenia uniflora and Parapiptadenia rigida. The families Myrtaceae, Meliaceae and Euphorbiaceae were the most representative families in the forest fragment studied. The Shannon diversity index was 3.
Key words: floristic composition, fitosociology, pau-ferro.

\section{INTRODUÇÃO}

A espécie Astronium balansae, pertencente à família Anacardiaceae, é denominada vulgarmente "pau-ferro" pelo fato de possuir madeira extremamente dura, pesada, resistente e durável (SCHULTZ, 1953). Esta espécie de crescimento lento está quase desaparecida no Rio Grande do Sul devido ao desmatamento indiscriminado. A vegetação de pauferro ocorre na forma de “capões” e é considerada como entidade fitogeográfica distinta do Rio Grande do Sul (LONGHI, 1987).

BELTRÃO et al. (1984) e FLEIG (1976) citam que o pau-ferro pertence à mata Chaqueana e ocorre entre Argentina, sul do Paraguai e Missões no Rio Grande do Sul. No Rio Grande do Sul, segundo BRASIL (1983) e BELTRÃO et al. (1984), o pau-ferro ocorre nos municípios de São Francisco de Assis, Santiago, Itaqui, São Borja, Santo Antônio das Missões, Bossoroca, São Luiz Gonzaga, São Nicolau, Roque Gonzales, Porto Xavier e Cerro Largo.

Sua distribuição está diretamente relacionada com afloramentos rochosos basálticos que

\footnotetext{
${ }^{1}$ Boligon e Hack, bolsistas de Iniciação Científica do Conselho Nacional de Desenvolvimento Científico e Tecnológico (CNPq), Programa Institucional de Bolsas de Iniciação Científica (PIBIC).

${ }^{2}$ Curso de Graduação em Agronomia, Universidade Federal de Santa Maria (UFSM), 97105-900, Santa Maria, RS, Brasil.

${ }^{3}$ Departamento de Ciências Florestais, Centro de Ciências Rurais (CCR), UFSM, 97105-900, Santa Maria, RS, Brasil. E-mail. longhiso@ccr.ufsm.br

${ }^{4}$ Programa de Pós-graduação em Engenharia Florestal, CCR, UFSM, 97105-900, Santa Maria, RS, Brasil.
} 
se intercalam com um solo mais evoluído. No habitat pedregoso, a vegetação é tipicamente dominada pelo pau-ferro que forma populações quase homogêneas. Ocorre associada a espécies como espinilho (Acacia caven), aroeira (Lithraea molleoides) e esporão-degalo (Celtis sp.) (BELTRÃO et al., 1984).

O pau-ferro está disperso em uma região que se apresenta como a mais quente do estado, com temperatura média anual variando de 17,9 a $20,1^{\circ} \mathrm{C}$. Apresenta boa quantidade e razoável distribuição de chuvas, com precipitação pluvial anual variando de 1.400 a $1.600 \mathrm{~mm}$ e 84 a 100 dias de chuva anuais. Possui ainda, os mais baixos valores de umidade relativa do ar do estado, variando de 72 a $75 \%$, altos valores de radiação solar global média (368 cal.cm².dia-1) e insolação (2.600 hs) , os mais altos valores de soma térmica do estado, com média anual de $3.500^{\circ} \mathrm{C}$, e o menor regime de frio do estado, com valores que variam de 350 a 600 horas de frio, no período entre maio e setembro (MALUF et al., 1999).

Pelo abundante conteúdo tânico, a madeira de pau-ferro torna-se muito durável, sendo por isso uma das mais usadas para a construção de postes, mourões e dormentes (FLEIG, 1976).

Para caracterizar o estágio de sucessão das comunidades utiliza-se a análise dos parâmetros fitossociológicos quantitativos e qualitativos. Os mais utilizados são densidade, dominância, freqüência, estrutura sociológica, Valor de Importância e Valor de Cobertura, além do Índice de Diversidade de Shannon.

A densidade pode ser definida como o número de indivíduos de cada espécie existentes na composição da comunidade, tendo sua forma absoluta (DA) e relativa (DR) (MATTEUCCI \& COLMA, 1982). A dominância é um parâmetro que expressa a proporção de tamanho ou cobertura de cada espécie em relação ao espaço da fitocenose (MARTINS, 1991), tanto na forma absoluta (DoA) como relativa (DoR). A freqüência é definida como a probabilidade de se amostrar determinada espécie numa unidade de amostragem (KUPPER, 1994), tendo forma absoluta (FA) e relativa (FR). Com a finalidade de dar um valor para as espécies dentro da comunidade vegetal a que pertencem é utilizado o Índice de Valor de Importância (VI), obtido pela soma dos valores relativos de densidade, dominância e freqüência (MATTEUCCI \& COLMA, 1982). Somando-se os valores relativos de densidade e dominância tem-se o Índice de Valor de Cobertura (VC), que é utilizado para expressar a importância das diferentes espécies na biocenose florestal (LONGHI, 1987).
A estrutura sociológica informa sobre a composição florística nos diferentes estratos da floresta em sentido vertical. A presença de espécies nos diferentes estratos é de fundamental importância fitossociológica, pois uma espécie tem presença assegurada na estrutura e dinâmica da floresta se bem representada em todos os seus estratos (LONGHI, 1987).

Para indicar a diversidade das espécies de uma comunidade vegetal, MARGURRAN (1988) cita que o Índice de Diversidade de Shannon (H’) é o mais usado pois combina o número de espécies presentes e a densidade relativa da espécie em um único valor.

Apesar do pau-ferro ser uma espécie bastante conhecida, pouco se sabe sobre o aspecto fitossociológico das associações das quais participa. Desta maneira, o presente trabalho teve como objetivo conhecer a composição florística e estrutura fitossociológica de um fragmento da Floresta Natural de Astronium balansae, no município de BossorocaRS.

\section{MATERIAL E MÉTODOS}

O presente trabalho foi realizado no município de Bossoroca, situado na região das Missões, noroeste do estado do Rio Grande do Sul. O fragmento florestal estudado possui uma área de 5ha e é uma associação sob a forma de "capões", muito típica desta região.

O clima da região, segundo a Classificação Climática de Köppen, é do tipo Cfa, subtropical de clima temperado chuvoso. Segundo MALUF et al. (1999), a temperatura máxima do mês mais quente, em dezembro, é de $39,8^{\circ} \mathrm{C}$ e a temperatura mínima do mês mais frio, em julho, é de $-2,6^{\circ} \mathrm{C}$. A temperatura média anual é de $17,9^{\circ} \mathrm{C}$. A precipitação média anual é de $1534 \mathrm{~mm} /$ ano (dados para o município de Santiago, no período de 1931-1960).

O solo da região é do tipo "Nitosolo Vermelho Distroférrico Latossólico” pertencente à unidade de mapeamento São Borja. É um solo com "B" textural, substrato basalto e com argila de atividade baixa (STRECK et al., 2002). Apresenta relevo ondulado a suavemente ondulado, caracterizado por elevações arredondadas (coxilhas) apresentando, em muitos locais, afloramentos rochosos. No interior do fragmento estudado, encontram-se afloramentos rochosos que se intercalam com solo mais profundo.

Para a coleta de dados a campo, utilizou-se a amostragem em faixas (PÉLLICO NETTO \& BRENA, 1997), sendo levantadas sete unidades amostrais de $10 \times 100 \mathrm{~m}\left(1000 \mathrm{~m}^{2}\right)$, perfazendo um total 
de 0,7ha. Em cada unidade amostral, foram consideradas todas as plantas com CAP (circunferência a altura do peito) maior ou igual a $30 \mathrm{~cm}$. De cada indivíduo, foram obtidos dados relativos a: espécie; CAP, medido com fita métrica; altura total e altura comercial, ambas medidas com Blume-Leiss; e posição sociológica, de acordo com estrato superior, médio ou inferior.

As espécies que não foram prontamente identificadas a campo, tiveram material botânico coletado para posterior identificação pelos taxonomistas do Herbário do Departamento de Ciências Florestais (HDCF) da Universidade Federal de Santa Maria.

De posse destes dados, estimaram-se o Índice de Diversidade de Shannon e os parâmetros fitossociológicos tradicionalmente utilizados para a descrição da estrutura horizontal e vertical da comunidade, os quais se encontram definidos nos trabalhos de LAMPRECHT (1964) e MATTEUCCI \& COLMA (1982). Para a verificação da suficiência amostral, foi utilizada a curva espécie-área, metodologia comum a este tipo de estudo. Para a obtenção destas estimativas, utilizou-se o programa FITOANÁLISE, elaborado por CARVALHO Jr. et al. (2002).

\section{RESULTADOS E DISCUSSÃO}

\section{Suficiência Amostral}

Ocorreu uma estabilização do número de espécies quando a área amostrada foi de $5000 \mathrm{~m}^{2}$ (Figura 1). Considerando o erro de $10 \%$ permitido para este tipo de metodologia, pode-se concluir que as 7 parcelas amostradas foram suficientes para representar a composição florística deste fragmento.

O fato do número de espécies ter se estabilizado com apenas 5 parcelas amostradas ocorreu devido à baixa diversidade florística deste tipo de vegetação. Alguns autores citam que florestas mais homogêneas resultam em curvas estabilizadas com menor área amostrada, e florestas muito heterogêneas tendem a ter estabilização apenas com elevadas áreas amostradas, não se estabilizando em certos casos (MANTOVANI, 1993; DIAS, 1993).

\section{Composição florística}

No total, foram observados 476 indivíduos com CAP $=30 \mathrm{~cm}$, pertencentes a 25 famílias, 33 gêneros e 35 espécies arbusto-arbóreas (Tabela 1). Além destas espécies, não foi possível a especificação de mais duas por falta de material fértil no período de coleta de dados.
O número reduzido de espécies é característica comum de capões, incluída a floresta de pau-ferro (LONGHI, 1987). Em trabalho em uma floresta de Astronium balansae, no município de São Borja -RS, o autor encontrou apenas 19 espécies. O número superior de espécies encontrado neste estudo pode ser explicado parcialmente pela ocorrência no fragmento de algumas espécies não características deste tipo de formação florestal. Assim, temos Ficus luschnathiana, que ocorre isolada em áreas de campo desta região, além de Allophyllus edulis, Cabralea canjerana, Trichilia catigua, T. elegans, Myrocarpus frondosus e Strychnos brasiliensis pertencentes à Floresta Estacional Decídua, próxima $15 \mathrm{~km}$ do fragmento. A maior proximidade destas formações, quando comparadas ao fragmento estudado por LONGHI (1987), juntamente com a ocorrência de solo mais evoluído no interior do fragmento, pode explicar a maior diversidade florística que este apresentou.

As famílias que mais se destacaram foram Myrtaceae, Meliaceae e Euphorbiaceae, representadas por 4, 3 e 3 espécies, respectivamente. Das 25 famílias amostradas, 17 (68\%) foram representadas por uma única espécie. A família que apresentou o maior número de indivíduos foi Myrtaceae, com 173 indivíduos, seguida por Boraginaceae, com 51, e Anacardiaceae, com 50 indivíduos. Estas 3 famílias somadas representaram $57,5 \%$ do total de indivíduos do fragmento. As espécies mais representadas foram Eugenia uniflora, com 90 indivíduos (18,9\% do total), Myrcianthes pungens, com 62 (13\%), Patagonula americana, com 51 (10,7\%), e Astronium balansae com $50(10,5 \%)$. Pode-se observar a grande dominância da família Myrtaceae em número de indivíduos, o que normalmente ocorre neste tipo de formação (LONGHI, 1987).

Estrutura horizontal da floresta

Analisando a tabela 2, observa-se um elevado número de indivíduos/ha equivalente a 680 árvores/ha, indicando que o fragmento se apresenta bastante denso.

Destacam-se Eugenia uniflora (128,57 árv.ha-1), Myrcianthes pungens (88,57 árv.ha-1), Patagonula americana (72,86 árv.ha- ${ }^{-1}$ ) e Astronium balansae (71,43 árv.ha-1), as espécies mais comuns e características deste tipo de vegetação.

As espécies Aspidosperma parvifolium, Eugenia uniflora e Schaefferia argentinensis ocorreram em todas as parcelas. Astronium balansae ocorreu em 6 parcelas, o que mostra que esta espécie tem distribuição aleatória neste fragmento. A presença 


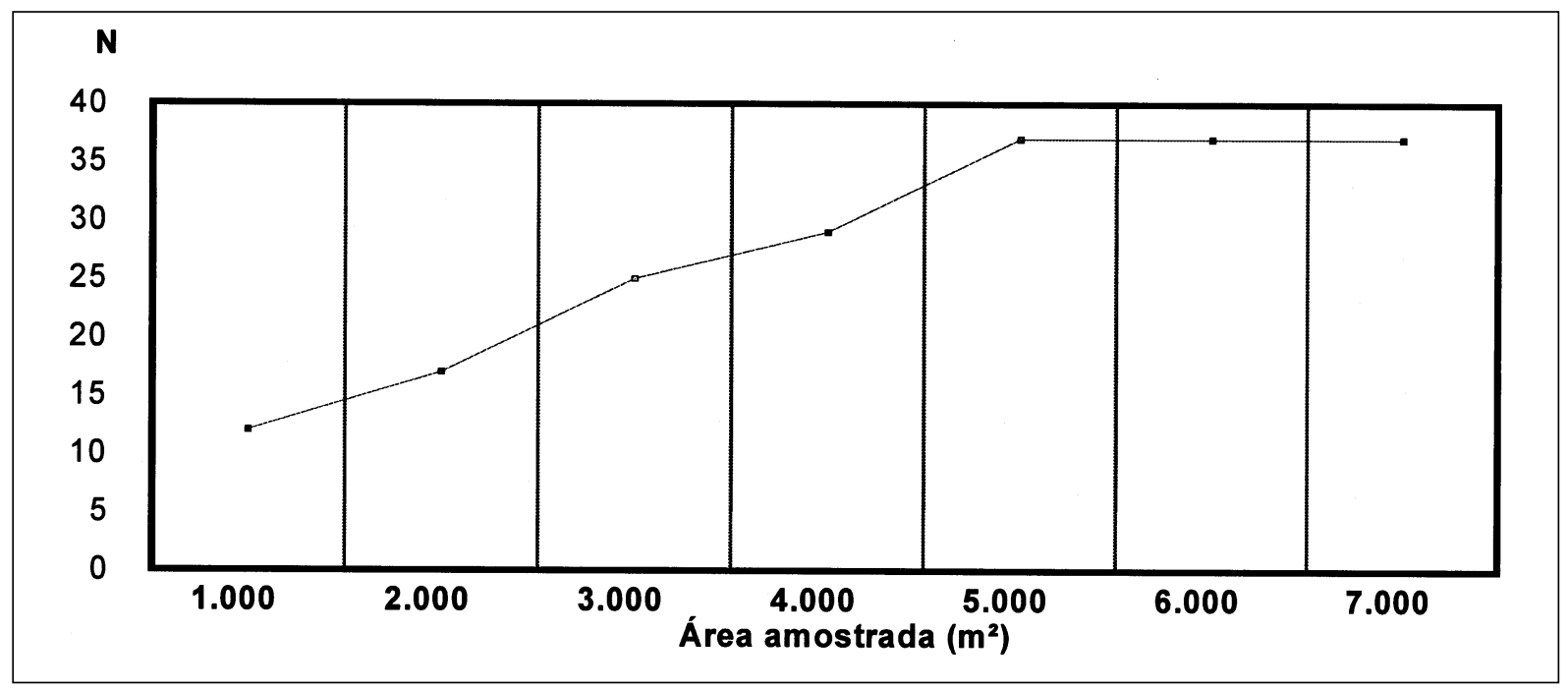

Figura 1 - Curva espécie/área de um fragmento de Floresta Natural de Astronium balansae, Bossoroca -RS

desta espécie em praticamente toda a área amostrada é devida às pequenas variações de solo e relevo dentro do capão de 5ha. Este fato só não é observado em capões onde houve extração de madeira de pau-ferro. As espécies com baixos valores de densidade e freqüência são comumente intituladas raras. Estas espécies são raras apenas no conceito numérico para uma determinada área num determinado momento, e não necessariamente do ponto de vista biológico, visto que podem ocorrer em florestas próximas à área de estudo (FIGUEIREDO, 1993). Porém, foram estas espécies que determinaram a diversidade florística deste fragmento. Neste grupo, devem existir algumas espécies verdadeiramente raras, considerando suas características biológicas, como aquelas de baixa densidade local por motivos sucessionais, sendo citadas as espécies Chomelia obtusa, Strychnos brasiliensis, Trichilia catigua e Allophylus edulis. Destas, as duas primeiras foram encontradas apenas nas bordas do fragmento, representando a transição deste com as áreas de campo nativo. Estas espécies podem determinar o avanço do capão sobre o campo. Devido ao estágio de sucessão secundária do fragmento, as demais espécies são suprimidas, diminuindo sua freqüência e densidade. Estas são encontradas nos locais onde o dossel não se encontra muito fechado e próximas às clareiras. Outras espécies, como Cabralea canjerana e Myrocarpus frondosus, apresentam baixa densidade por serem espécies de outras formações.

Observa-se que Astronium balansae é a mais dominante, perfazendo 21,66\% da dominância total. Esta é seguida por Patagonula americana
(17,43\%) e Myrcianthes pungens (16,19\%). A dominância destas espécies se deve, principalmente, às grandes dimensões de seus indivíduos.

Quando as espécies foram hierarquizadas pelo VI, houve a seguinte seqüência: Astronium balansae $(12,57 \%$ do VI total), Myrcianthes pungens (11,9\%), Patagonula americana (11,54\%), Eugenia uniflora (9,64\%) e Parapiptadenia rigida (8,35\%). Estas cinco espécies perfazem $54 \%$ do VI total deste fragmento. Destas, Eugenia uniflora teve elevado VI devido à sua elevada freqüência e densidade. As demais espécies apresentaram, além de elevada freqüência e densidade, valores elevados de dominância, o que contribuiu para seu maior VI.

Para o valor de cobertura, tem-se a mesma hierarquia citada para o VI, sendo que estas mesmas espécies perfazem 66,18\% do VC total. O elevado VC é devido à grande densidade e dominância destas espécies. Estes valores comprovam que estas são as espécies mais características e importantes do tipo de vegetação considerado neste levantamento.

O baixo número de árvores mortas encontradas (1,43 árv.ha-1 ${ }^{-1}$, representando $0,21 \%$ do total, é devido ao fato das mesmas serem retiradas do local para utilização na propriedade. O valor estimado do índice de diversidade de Shannon encontrado para o fragmento foi de 3,0, ficando próximo ao encontrado por LONGHI et al.(2000) para um fragmento de Floresta Estacional Decidual no município de Santa Maria-RS (3,213), e por LONGHI et al. (1999) que encontrou índice de diversidade de 3,12, estudando outro fragmento da mesma região.

Ciência Rural, v. 35, n. 5, set-out, 2005. 
Tabela 1 - Famílias, espécies e nomes comuns para espécies com CAP $=30 \mathrm{~cm}$, amostradas em um fragmento da floresta natural de Astronium balansae, Bossoroca -RS.

\begin{tabular}{|c|c|c|}
\hline Família & Nome científico & Nome vulgar \\
\hline Achatocarpaceae & Achatocarpus praecox Griseb. & Cabo-de-lança \\
\hline Anacardiaceae & Astronium balansae Engl. & Pau-ferro \\
\hline Annonaceae & Rollinia sp. & Ariticum \\
\hline Apocynaceae & Aspidosperma parvifolium DC. & Guatambu \\
\hline Bignoniaceae & Tabebuia heptaphylla (Vell.) Toledo & Ipê-roxo \\
\hline Boraginaceae & Patagonula americana L. & Guajuvira \\
\hline Caesalpiniaceae & Holocalyx balansae Micheli & Alecrim \\
\hline Celastraceae & Schaefferia argentinensis Speg. & Falsa-coronilha \\
\hline \multirow{3}{*}{ Euphorbiaceae } & Gymnanthes concolor Spreng. & Laranjeira-do-mato \\
\hline & Sebastiania brasiliensis Spreng. & Branquilho-leiteiro \\
\hline & Sebastiania commersoniana (Baill.) L. B. Sm. et Downs & Branquilho-comum \\
\hline Fabaceae & Myrocarpus frondosus M. Allemão & Cabriúva \\
\hline Flacourtiaceae & Xylosma prockia (Turcz.) Turcz. & Sucará \\
\hline Lauraceae & Nectandra megapotamica (Spreng.) Mez & Canela-preta \\
\hline Loganiaceae & Strychnos brasiliensis (Spreng.) Mart. & Anzol-de-lontra \\
\hline \multirow{3}{*}{ Meliaceae } & Cabralea canjerana (Vell.) Mart. & Canjerana \\
\hline & Trichilia catigua A.-Juss. & Catiguá-verdadeiro \\
\hline & Trichilia elegans A.-Juss. & Catiguá-de-ervilha \\
\hline Mimosaceae & Parapiptadenia rigida (Benth.) Brenan & Angico-vermelho \\
\hline \multirow{2}{*}{ Moraceae } & Ficus luschnathiana (Miq.) Miq. & Figueira-do-mato \\
\hline & Sorocea bonplandii (Baill.) W. C. Burger et al. & Cincho \\
\hline Morta & Morta & Morta \\
\hline \multirow{4}{*}{ Myrtaceae } & Campomanesia guazumifolia (Cambess.) O. Berg & Sete-capotes \\
\hline & Eugenia uniflora L. & Pitangueira \\
\hline & Myrcianthes pungens (O. Berg) D. Legrand & Guabijú \\
\hline & Plinia rivularis (Cambess.) Rotman & Guapurití \\
\hline NI & Não identificada & NI \\
\hline Polygonaceae & Ruprechtia laxiflora Meisn. & Marmeleiro-do-mato \\
\hline \multirow{2}{*}{ Rubiaceae } & Chomelia obtusa Cham. et Schltdl. & Viuvinha \\
\hline & Guettarda uruguensis Cham. et Schltdl. & Veludinho \\
\hline \multirow{2}{*}{ Rutaceae } & Helietta apiculata Benth. & Canela-de-veado \\
\hline & Zanthoxylum rhoifolium L. & Mamica-de-cadela \\
\hline Sapindaceae & Allophylus edulis (A. St.-Hil. et al.) Radlk. & Chal-chal \\
\hline \multirow{2}{*}{ Sapotaceae } & Chrysophyllum gonocarpum (Mart. \& Eichler) Engl. & Aguaí-da-serra \\
\hline & Chrysophyllum marginatum (Hook. et Arn.) Radlk. & Aguaí-leiteiro \\
\hline Ulmaceae & Celtis iguanaea (Jacq.) Sargent & Esporão-de-galo \\
\hline Verbenaceae & Vitex megapotamica (Spreng.) Moldenke & Tarumã \\
\hline
\end{tabular}

Estrutura vertical da floresta

A tabela 3 mostra dados da análise da estrutura Sociológica Vertical do fragmento estudado. Pode-se verificar que o total de indivíduos deste fragmento encontra-se bem distribuído nos três estratos. O estrato inferior possui número de indivíduos um pouco maior devido ao grande número de árvores jovens encontradas no local, principalmente mirtáceas, normal para florestas inequiâneas.

Observa-se que a espécie Astronium balansae foi a mais importante do estrato superior (com $23,53 \%$ dos indivíduos totais do estrato) concentrando $64 \%$ de seus indivíduos neste estrato. É a terceira mais importante do estrato médio (10,20\%), com $30 \%$ de seus indivíduos, e apenas a oitava (1,55\%) do estrato inferior, com $6 \%$ de seus indivíduos. Isto comprova o caráter heliófilo desta espécie. Este fato também foi verificado por LONGHI (1987), que encontrou apenas $12,21 \%$ dos indivíduos da espécie no estrato inferior, em outro fragmento de Floresta Natural de Astronium balansae. Esta espécie tende a ser substituída no futuro por umbrófitas na dinâmica do fragmento.

Além desta, outras espécies representativas do estrato superior foram Patagonula americana (16,91\% dos indivíduos deste estrato), Myrcianthes pungens

Ciência Rural, v.35 n. 5, set-out, 2005. 
Tabela 2 - Parâmetros fitossociológicos das espécies com CAP $=30 \mathrm{~cm}$, amostradas em um fragmento da floresta natural de Astronium balansae, Bossoroca, RS.

\begin{tabular}{|c|c|c|c|c|c|c|c|c|c|c|}
\hline Espécie & DA & DR & DoA & DoR & FA & FR & VI & VC & VI\% & $\mathrm{VC} \%$ \\
\hline Achatocarpus praecox & 8,57 & 1,26 & 0,18 & 0,51 & 14,29 & 0,93 & 2,70 & 1,77 & 0,90 & 0,88 \\
\hline Allophylus edulis & 2,86 & 0,42 & 0,07 & 0,21 & 14,29 & 0,93 & 1,55 & 0,63 & 0,52 & 0,31 \\
\hline Aspidosperma parvifolium & 8,57 & 1,26 & 0,33 & 0,93 & 42,86 & 2,78 & 4,96 & 2,19 & 1,65 & 1,09 \\
\hline Astronium balansae & 71,43 & 10,50 & 7,65 & 21,66 & 85,71 & 5,56 & 37,72 & 32,16 & 12,57 & 16,08 \\
\hline Cabralea canjerana & 1,43 & 0,21 & 0,02 & 0,07 & 14,29 & 0,93 & 1,20 & 0,28 & 0,40 & 0,14 \\
\hline Campomanesia guazumifolia & 11,43 & 1,68 & 0,22 & 0,62 & 57,14 & 3,70 & 6,01 & 2,30 & 2,00 & 1,15 \\
\hline Celtis iguanaea & 1,43 & 0,21 & 0,01 & 0,03 & 14,29 & 0,93 & 1,17 & 0,24 & 0,39 & 0,12 \\
\hline Chomelia obtusa & 1,43 & 0,21 & 0,05 & 0,14 & 14,29 & 0,93 & 1,27 & 0,35 & 0,42 & 0,17 \\
\hline Chrysophyllum gonocarpum & 2,86 & 0,42 & 0,03 & 0,08 & 14,29 & 0,93 & 1,42 & 0,50 & 0,47 & 0,25 \\
\hline Chrysophyllum marginatum & 14,29 & 2,10 & 0,71 & 2,02 & 57,14 & 3,70 & 7,82 & 4,12 & 2,61 & 2,06 \\
\hline Eugenia uniflora & 128,6 & 18,91 & 1,57 & 4,44 & 85,71 & 5,56 & 28,91 & 23,35 & 9,64 & 11,68 \\
\hline Ficus luschnathiana & 4,29 & 0,63 & 0,14 & 0,38 & 14,29 & 0,93 & 1,94 & 1,01 & 0,65 & 0,51 \\
\hline Guettarda uruguensis & 1,43 & 0,21 & 0,01 & 0,03 & 14,29 & 0,93 & 1,17 & 0,24 & 0,39 & 0,12 \\
\hline Gymnanthes concolor & 4,29 & 0,63 & 0,04 & 0,10 & 28,57 & 1,85 & 2,59 & 0,73 & 0,86 & 0,37 \\
\hline Helietta apiculata & 28,57 & 4,20 & 1,37 & 3,87 & 85,71 & 5,56 & 13,62 & 8,07 & 4,54 & 4,03 \\
\hline Holocalyx balansae & 10,00 & 1,47 & 1,18 & 3,35 & 14,29 & 0,93 & 5,74 & 4,82 & 1,91 & 2,41 \\
\hline Morta & 1,43 & 0,21 & 0,02 & 0,04 & 14,29 & 0,93 & 1,18 & 0,25 & 0,39 & 0,13 \\
\hline Myrcianthes pungens & 88,57 & 13,03 & 5,72 & 16,19 & 100,0 & 6,48 & 35,70 & 29,22 & 11,90 & 14,61 \\
\hline Myrocarpus frondosus & 1,43 & 0,21 & 0,02 & 0,05 & 14,29 & 0,93 & 1,18 & 0,26 & 0,39 & 0,13 \\
\hline Não identificada & 2,86 & 0,42 & 0,09 & 0,25 & 28,57 & 1,85 & 2,52 & 0,67 & 0,84 & 0,33 \\
\hline Nectandra megapotamica & 5,71 & 0,84 & 0,52 & 1,49 & 42,86 & 2,78 & 5,10 & 2,33 & 1,70 & 1,16 \\
\hline Parapiptadenia rígida & 45,71 & 6,72 & 4,51 & 12,76 & 85,71 & 5,56 & 25,04 & 19,49 & 8,35 & 9,74 \\
\hline Patagonula americana & 72,86 & 10,71 & 6,15 & 17,43 & 100 & 6,48 & 34,62 & 28,14 & 11,54 & 14,07 \\
\hline Plinia rivularis & 18,57 & 2,73 & 0,31 & 0,88 & 71,43 & 4,63 & 8,24 & 3,61 & 2,75 & 1,81 \\
\hline Rollinia sp. & 11,43 & 1,68 & 0,30 & 0,85 & 42,86 & 2,78 & 5,31 & 2,53 & 1,77 & 1,27 \\
\hline Ruprechtia laxiflora & 5,71 & 0,84 & 0,36 & 1,01 & 42,86 & 2,78 & 4,63 & 1,85 & 1,54 & 0,93 \\
\hline Schaefferia argentinensis & 5,71 & 0,84 & 0,17 & 0,49 & 14,29 & 0,93 & 2,26 & 1,33 & 0,75 & 0,67 \\
\hline Sebastiania brasiliensis & 44,29 & 6,51 & 0,75 & 2,13 & 85,71 & 5,56 & 14,20 & 8,64 & 4,73 & 4,32 \\
\hline Sebastiania commersoniana & 21,43 & 3,15 & 0,39 & 1,12 & 42,86 & 2,78 & 7,04 & 4,27 & 2,35 & 2,13 \\
\hline Sorocea bonplandii & 2,86 & 0,42 & 0,04 & 0,10 & 14,29 & 0,93 & 1,45 & 0,52 & 0,48 & 0,26 \\
\hline Strychnos brasiliensis & 2,86 & 0,42 & 0,04 & 0,12 & 14,29 & 0,93 & 1,47 & 0,54 & 0,49 & 0,27 \\
\hline Tabebuia heptaphylla & 20,00 & 2,94 & 1,30 & 3,69 & 100,0 & 6,48 & 13,11 & 6,63 & 4,37 & 3,31 \\
\hline Trichilia catigua & 1,43 & 0,21 & 0,03 & 0,08 & 14,29 & 0,93 & 1,22 & 0,29 & 0,41 & 0,15 \\
\hline Trichilia elegans & 7,14 & 1,05 & 0,26 & 0,73 & 28,57 & 1,85 & 3,63 & 1,78 & 1,21 & 0,89 \\
\hline Vitex megapotamica & 10,00 & 1,47 & 0,23 & 0,65 & 42,86 & 2,78 & 4,90 & 2,12 & 1,63 & 1,06 \\
\hline Xylosma prockia & 4,29 & 0,63 & 0,46 & 1,30 & 42,86 & 2,78 & 4,70 & 1,93 & 1,57 & 0,96 \\
\hline Zanthoxylum rhoifolium & 4,29 & 0,63 & 0,07 & 0,21 & 28,57 & 1,85 & 2,69 & 0,84 & 0,90 & 0,42 \\
\hline Total & 680 & 100 & 35,3 & 100 & $1.542,8$ & 100 & 300 & 200 & 100 & 100 \\
\hline
\end{tabular}

Em que: DA = densidade absoluta; DR = densidade relativa; DoA = dominância absoluta; DoR = dominância relativa; FA = freqüência absoluta;; FR = freqüência relativa; VI = valor de importância; VC = valor de cobertura.

(16,18\%) e Parapiptadenia rigida (11,76\%). Estas espécies dominaram o estrato superior, devido à maior densidade de indivíduos de grande porte e apresentaram-se bem distribuídas em todos os estratos, fato que garante a permanência destas na dinâmica futura do fragmento.

Destacaram-se ainda, Xylosma prockia e

Nectandra megapotamica pela presença restrita ao estrato superior, o que nos leva a concluir que tendem a ser substituídas por outras espécies no futuro.
Analisando-se o estrato inferior, nota-se que Eugenia uniflora é dominante, representando $41,45 \%$ dos indivíduos do estrato, concentrando $88,89 \%$ de todos os representantes desta espécie. Este fato é explicado pelo baixo porte da espécie, o que não permite que alcance os estratos mais altos da floresta.

Outras espécies de pequeno porte que se destacaram por terem $100 \%$ de seus indivíduos no

Ciência Rural, v. 35, n. 5, set-out, 2005. 
Aspectos fitossociológicos de um fragmento da floresta natural de Astronium balansae engl., no município de Bossoroca, RS. 1081

Tabela 3 - Estrutura sociológica vertical de um fragmento da Floresta Natural de Astronium balansae, Bossoroca-RS (valores/ha).

\begin{tabular}{|c|c|c|c|c|c|c|c|c|c|}
\hline \multirow{3}{*}{ Nome científico } & \multicolumn{9}{|c|}{ Estratos Arbóreos } \\
\hline & \multicolumn{3}{|c|}{1} & \multicolumn{3}{|c|}{2} & \multicolumn{3}{|c|}{3} \\
\hline & $\mathrm{N}$ & $\%$ esp. & $\%$ est. & $\mathrm{N}$ & $\%$ esp. & $\%$ est. & $\mathrm{N}$ & $\%$ esp. & $\%$ est. \\
\hline Achatocarpus praecox & 0,00 & 0,00 & 0,00 & 2,86 & 1,36 & 33,33 & 5,71 & 2,07 & 66,67 \\
\hline Allophylus edulis & 1,43 & 0,74 & 50,00 & 1,43 & 0,68 & 50,00 & 0,00 & 0,00 & 0,00 \\
\hline Aspidosperma parvifolium & 2,86 & 1,47 & 33,33 & 1,43 & 0,68 & 16,67 & 4,29 & 1,55 & 50,00 \\
\hline Astronium balansae & 45,71 & 23,53 & 64,00 & 21,43 & 10,20 & 30,00 & 4,29 & 1,55 & 6,00 \\
\hline Cabralea canjerana & 0,00 & 0,00 & 0,00 & 0,00 & 0,00 & 0,00 & 1,43 & 0,52 & 100,00 \\
\hline Campomanesia guazumifolia & 2,86 & 1,47 & 25,00 & 5,71 & 2,72 & 50,00 & 2,86 & 1,04 & 25,00 \\
\hline Celtis iguanaea & 0,00 & 0,00 & 0,00 & 0,00 & 0,00 & 0,00 & 1,43 & 0,52 & 100,00 \\
\hline Chomelia obtusa & 0,00 & 0,00 & 0,00 & 0,00 & 0,00 & 0,00 & 1,43 & 0,52 & 100,00 \\
\hline Chrysophyllum gonocarpum & 1,43 & 0,74 & 50,00 & 0,00 & 0,00 & 0,00 & 1,43 & 0,52 & 50,00 \\
\hline Chrysophyllum marginatum & 2,86 & 1,47 & 20,00 & 7,14 & 3,40 & 50,00 & 4,29 & 1,55 & 30,00 \\
\hline Eugenia uniflora & 0,00 & 0,00 & 0,00 & 14,29 & 6,80 & 11,11 & 114,29 & 41,45 & 88,89 \\
\hline Fícus luschnathiana & 0,00 & 0,00 & 0,00 & 2,86 & 1,36 & 66,67 & 1,43 & 0,52 & 33,33 \\
\hline Guettarda uruguensis & 0,00 & 0,00 & 0,00 & 1,43 & 0,68 & 100,00 & 0,00 & 0,00 & 0,00 \\
\hline Gymnanthes concolor & 0,00 & 0,00 & 0,00 & 0,00 & 0,00 & 0,00 & 4,29 & 1,55 & 100,00 \\
\hline Helietta apiculata & 11,43 & 5,88 & 40,00 & 14,29 & 6,80 & 50,00 & 2,86 & 1,04 & 10,00 \\
\hline Holocalyx balansae & 5,71 & 2,94 & 57,14 & 4,29 & 2,04 & 42,86 & 0,00 & 0,00 & 0,00 \\
\hline Morta & 0,00 & 0,00 & 0,00 & 0,00 & 0,00 & 0,00 & 1,43 & 0,52 & 100,00 \\
\hline Myrcianthes pungens & 31,43 & 16,18 & 35,48 & 38,57 & 18,37 & 43,55 & 18,57 & 6,74 & 20,97 \\
\hline Myrocarpus frondosus & 0,00 & 0,00 & 0,00 & 1,43 & 0,68 & 100,00 & 0,00 & 0,00 & 0,00 \\
\hline Não identificada & 1,43 & 0,74 & 50,00 & 1,43 & 0,68 & 50,00 & 0,00 & 0,00 & 0,00 \\
\hline Nectandra megapotamica & 5,71 & 2,94 & 100,00 & 0,00 & 0,00 & 0,00 & 0,00 & 0,00 & 0,00 \\
\hline Parapiptadenia rigida & 22,86 & 11,76 & 50,00 & 14,29 & 6,80 & 31,25 & 8,57 & 3,11 & 18,75 \\
\hline Patagonula americana & 32,86 & 16,91 & 45,10 & 22,86 & 10,88 & 31,37 & 17,14 & 6,22 & 23,53 \\
\hline Plinia rivularis & 0,00 & 0,00 & 0,00 & 2,86 & 1,36 & 15,38 & 15,71 & 5,70 & 84,62 \\
\hline Rollinia sp. & 0,00 & 0,00 & 0,00 & 8,57 & 4,08 & 75,00 & 2,86 & 1,04 & 25,00 \\
\hline Ruprechtia laxiflora & 4,29 & 2,21 & 75,00 & 0,00 & 0,00 & 0,00 & 1,43 & 0,52 & 25,00 \\
\hline Schaefferia argentinensis & 1,43 & 0,74 & 25,00 & 0,00 & 0,00 & 0,00 & 4,29 & 1,55 & 75,00 \\
\hline Sebastiania brasiliensis & 1,43 & 0,74 & 3,23 & 10,00 & 4,76 & 22,58 & 32,86 & 11,92 & 74,19 \\
\hline Sebastiania commersoniana & 0,00 & 0,00 & 0,00 & 8,57 & 4,08 & 40,00 & 12,86 & 4,66 & 60,00 \\
\hline Sorocea bonplandii & 0,00 & 0,00 & 0,00 & 0,00 & 0,00 & 0,00 & 2,86 & 1,04 & 100,00 \\
\hline Strychnos brasiliensis & 0,00 & 0,00 & 0,00 & 2,86 & 1,36 & 100,00 & 0,00 & 0,00 & 0,00 \\
\hline Tabebuia heptaphylla & 10,00 & 5,15 & 50,00 & 7,14 & 3,40 & 35,71 & 2,86 & 1,04 & 14,29 \\
\hline Trichilia catigua & 0,00 & 0,00 & 0,00 & 1,43 & 0,68 & 100,00 & 0,00 & 0,00 & 0,00 \\
\hline Trichilia elegans & 0,00 & 0,00 & 0,00 & 5,71 & 2,72 & 80,00 & 1,43 & 0,52 & 20,00 \\
\hline Vitex megapotamica & 1,43 & 0,74 & 14,29 & 7,14 & 3,40 & 71,43 & 1,43 & 0,52 & 14,29 \\
\hline Xylosma prockia & 4,29 & 2,21 & 100,00 & 0,00 & 0,00 & 0,00 & 0,00 & 0,00 & 0,00 \\
\hline Zanthoxylum rhoifolium & 2,86 & 1,47 & 66,67 & 0,00 & 0,00 & 0,00 & 1,43 & 0,52 & 33,33 \\
\hline Total & 194,3 & & & 210,00 & & & 275,71 & & \\
\hline
\end{tabular}

Em que: $\mathrm{N}$ = número de indivíduos; \% esp. = percentagem do estrato em questão representada pela espécie; \% est. = percentagem de indivíduos da espécie que se encontram no estrato em questão.

estrato inferior foram Chomelia obtusa, Celtis iguanaea e Gymnanthes concolor, embora representem uma pequena fração deste devido à sua baixa densidade.

A ocorrência de um indivíduo jovem de Cabralea canjerana no estrato inferior indica que esta espécie está se estabelecendo neste local há pouco tempo, onde encontre condições favoráveis, principalmente no que diz respeito à luminosidade (clareiras no interior da mata ou condição de borda), dado ser espécie pioneira. Esta espécie não é comum a este tipo de formação florestal, sendo característica da Floresta Estacional Decídua, próxima ao fragmento estudado. A abertura de clareiras, possivelmente pela 
retirada de madeira do local, bem como condições adequadas de solo em certos locais da área (sem afloramento de rochas), beneficiam o aparecimento desta espécie. Assim, esta poderá ser encontrada no futuro ocorrendo juntamente com os capões de pauferro desta região.

\section{CONCLUSÕES}

A espécie mais característica e importante deste tipo de formação é Astronium balansae (pauferro) por apresentar maior dominância, maior Índice de Valor de Importância e maior Índice de Valor de Cobertura. Seu maior número de indivíduos se apresenta no estrato superior, devido ser esta uma espécie heliófila. As outras espécies que se destacaram neste fragmento foram Myrcianthes pungens, Patagonula americana, Eugenia uniflora e Parapiptadenia rigida.

As espécies que apresentaram baixa densidade e freqüência no estrato inferior tendem a ser substituídas na sucessão futura do fragmento por espécies de formações próximas como da Floresta Estacional Decídua, aumentando assim, a diversidade florística do fragmento estudado.

A baixa diversidade florística do fragmento é característica das formações sob a forma de capões, típicas das regiões campestres encontradas no local de estudo. Espera-se, como tendência natural deste tipo de formação, o avanço da vegetação dos capões sobre a vegetação campestre.

\section{REFERÊNCIAS}

BELTRÃO, L. et al. Desenvolvimento de tecnologia para exploração florestal de "pau-ferro" (Astronium balansae Engl.). In: CONGRESSO FLORESTAL ESTADUAL, 5 , 1984, Nova Prata. Anais... Nova Prata: Prefeitura Municipal, 1984. p. 521 523.

BRASIL. Instituto Brasileiro de Desenvolvimento Florestal. Inventário florestal nacional - Florestas nativas do Rio Grande do Sul. Brasília: 1983. 345 p.

CARVALHO Jr., L.A. et al. FITOANÁLISE - Software para análise fitossociológica e inventário florestal. Santa Maria: UFSM, 2002.

DIAS, A.C. Estrutura e diversidade do componente arbóreo e a regeneração do palmito (Euterpe edulis) de um trecho da mata secundária no Parque Estadual de Carlos Botelho (SP). 1993. 126f. Dissertação (Mestrado em Engenharia Florestal) - ESALQ/USP.
FIGUEIREDO, N. Estudo fitossociológico em uma floresta mesófila semidecídua secundária na Estação Experimental de Angatuba, município de Angatuba, SP. 1993. 160f. Dissertação (Mestrado em Engenharia Florestal) - Universidade Estadual de Campinas.

FLEIG, M. Estudo taxonômico da família Anacardiaceae no Rio Grande do Sul, Brasil. 1976. 163f. Dissertação (Mestrado em Botânica) - URGS.

KUPPER, A. Recuperação vegetal com espécies nativas. Silvicultura, São Paulo, v.15, n.58, p.38-41, nov./dez. 1994.

LAMPRECHT, H. Ensayo sobre la estrutura floristica de la parte sur - oriental del bosque universitario "El Caimital", Estado Barinas. Rev. For. Venezolana, Mérida, v. 7, n. 10/11, p. 77119, 1964.

LONGHI, S. J. Aspéctos fitossociológicos de uma floresta natural de Astronium balansae Engl., no Rio Grande do Sul. Revista do Centro de Ciências Rurais, Santa Maria, v. 17, n. 1, p. $49-$ 61, 1987.

LONGHI, S.J. et al. Aspectos fitossociológicos de fragmento de Floresta Estacional Decidual, Santa Maria, RS. Ciência Florestal, Santa Maria, v.10, n.2, p.59-74, 2000.

LONGHI, S.J. et al. Composição florística e estrutura da comunidade arbórea de um fragmento florestal no município de Santa Maria - Brasil. Ciência Florestal, v. 9, n. 1, p. 115133, 1999.

MALUF, J.R.T. et al. Características climáticas da região de dispersão natural de Pau-Ferro (Astronium balansae Engl.) no estado do Rio Grande do Sul. Pesquisa em andamento Online n. 4 - Publicações - Embrapa Trigo, 1999. Disponível no site: www.embrapa.com.br

MANTOVANI, W. Estrutura dinâmica da floresta atlântica na Juréia - SP. 1993. 128p. Tese (LivreDocência) - Instituto de Biociências, Universidade de São Paulo.

MARGURRAN, A.E. Ecological Diversity and its Measurements. New Jersey: Princeton University. 1988. 200p.

MARTINS, F.R. Estrutura de uma floresta mesófila. Campinas: UNICAMP, 1991. 246p.

MATTEUCCI, S.D.; COLMA, A. Metodologia para el estudio de la vegetacion. Washington: The Genral Secretarial of the Organization of American States, 1982. 167p. (Série Biologia - Monografia, 22).

PÉLLICO NETTO, S.; BRENA, D.A. Inventário florestal. Curitiba: editorado pelos autores, 1997. 316p.

SCHULTZ, A.R. Pau-ferro no Rio Grande do Sul. Porto Alegre: Instituto Tecnológico do Rio Grande do Sul, 1953. 9p. (Boletim técnico, 23).

STRECK, E.V. et al. Solos do Rio Grande do Sul. Porto Alegre: EMATER/RS; URGS, 2002. 